\title{
Um estudo acerca dos cursos de formação de professores de língua estrangeira e o paradigma contemporâneo
}

\author{
Enrique Huelva Unternbäumen (UNTERNBÄUMEN, Enrique H.) \\ Professor Doutor da Universidade de Brasília - UnB \\ huelva@unb.br
}

Ana Carolina Nunes Araújo (ARAÚJO, Ana Carolina N.)

Professora Mestre do Centro Universitário Unieuro

anacarolinana@gmail.com

\section{Resumo}

Este artigo descreve uma pesquisa que investigou três cursos de Licenciatura em Língua Estrangeira (espanhola, francesa e inglesa) em uma universidade federal do Brasil, quanto a se estão, de fato, preparando os professores para a prática docente em conformidade com os parâmetros teóricos contemporâneos. De cada curso, colaboraram três professoras em formação cursando o último semestre e uma professora formadora, perfazendo um total de 12 participantes. Foram usados questionários abertos com questões sobre o curso, as disciplinas e conhecimentos considerados necessários ao professor em formação. Os resultados sugerem que os cursos investigados têm sua base mais próxima do paradigma estruturalista que do paradigma comunicativo contemporâneo. As participações sugerem que a base teórica oferecida aos professores em formação não mostra ser completamente consistente com os fundamentos para o ensino de línguas comunicativo. Desta forma, identificam-se lacunas na estrutura dos cursos investigados as quais demandam correção para chegarmos a uma formação de professores de línguas que vá ao encontro de toda a produção teórica já disponível para essa tarefa.

Palavras-chaves: língua, cultura, abordagem comunicativa, competência comunicativa, formação de professores

\begin{abstract}
The research here described investigated three Under-graduate Courses for Foreign Language Teacher Education (languages were Spanish, French and English) aiming to find out whether the courses are structured to educate teachers in accordance to the contemporary theoretical parameters for foreign language teachers education. We invited three prospective teachers taking the last semester of the course and one teacher educator for each course, making up a total of 12 participants. Open questionnaires were used, containing questions about the course, about some of the subjects and about knowledge of some basic elements considered central for teacher education. The results suggest that the three Under-graduate Courses for Foreign Language Teacher studied still present a strong influence of structuralism in contrast with the characteristics of the contemporary communicative paradigm for language teaching. The data collected
\end{abstract}


suggest that the theoretical basis offered by the course is not completely coherent with the precepts for the Communicative Approach and for the communicative teaching. Therefore, a gap in the structure of the Under-graduate Courses for Foreign Language Teacher Education is clearly identified, which demands rapid action if we are to reach the level of Teacher Education aimed at by the vast theoretical basis available for that end.

Keywords: language, culture, communicative approach, communicative competence, teacher education

\section{Introdução}

O contexto contemporâneo, marcado "por novos fenômenos e tendências irreversíveis como a globalização e a interação entre culturas" (RAJAGOPALAN, 2003, p.25), impõe suas demandas sobre o processo de ensino-aprendizagem de línguas e sobre o professor de línguas. Em virtude deste grande contato entre povos e culturas, cada vez mais estudiosos e pesquisadores concordam que uma língua estrangeira deve ser ensinada para a comunicação, visando à interação. Atualmente, a Abordagem Comunicativa tem sido vista por alguns teóricos e estudiosos da Linguística Aplicada como proposta metodológica que pode atender a essa necessidade de desenvolver nos aprendentes a Competência Comunicativa, ou seja, a capacidade de comunicação na nova língua e de fazer frente às oportunidades de interação e construção de significados.

Acreditamos que ao buscarmos saber o que se espera, ou se requer, de um professor de línguas, cabe-nos antes questionar e debater o papel e o desempenho das instituições que os formam. Partindo dessa premissa, apresenta-se a seguinte questão: Como os preceitos fundamentais para a Abordagem Comunicativa e para o ensino da Competência Comunicativa são abordados durante o curso de Licenciatura?

Neste artigo, expomos os resultados de uma pesquisa realizada no Instituto de Letras de uma universidade pública. Buscamos investigar aspectos específicos de três cursos de Licenciatura para verificar se estão presentes nestes elementos suficientes que garantam ao professor recém-formado uma base de conhecimento teórico e oportunidades de prática satisfatórias que lhe permitam atuar com segurança para um ensino de línguas comunicativo. Procuramos fazer isso a partir de dois pontos de vista, a saber, das professoras em formação e das professoras formadoras. Assim, buscamos criar um breve panorama da condição atual do processo de formação de professores de línguas nos cursos investigados. 


\section{Fundamentação teórica}

\section{Língua e cultura}

O primeiro passo que possibilita ao professor de línguas auxiliar e ensinar outros a atravessar a ponte do contato entre culturas é compreender claramente o que é língua e qual sua relação com cultura. A nossa primeira língua, ou língua materna, é aquela na qual constituímos nossa identidade pessoal, regional, étnica e cultural, e é manifestada por meio de um dialeto ou variante regional em combinação com outros fatores, tais como traços étnicos e de classe social (ALMEIDA FILHO, 2007, p. 64). Kramsch (1988, p. 3, 8, 97) afirma que nossa língua é o principal meio que usamos para conduzirmos nossa vida social e está intimamente relacionada com o que pensamos, como nos comportamos e como influenciamos o comportamento de outros; permeia nossos pensamentos e nossa forma de ver o mundo. Sobre a relação entre língua e cultura, a autora afirma ainda que a língua não é um código dependente da cultura, mas tem um papel significativo na perpetuação desta.

É por meio das interações que os indivíduos pertencentes a um determinado grupo cultural comunicam seu conjunto de significações culturais, os quais compreendem a visão de mundo, as explicações e interpretações da realidade, as formas de organizar e lidar com o contexto que a todos envolve. Assim sendo, podemos pensar cultura como um modo de vida, "o contexto no qual existimos, pensamos, sentimos e nos relacionamos com outros" (BROWN, 2007, p. 188). Essa forma de pensar a cultura realça sua convergência com a comunicação e a interação por meio da linguagem.

Com a transição do paradigma estruturalista para o comunicativo, tem sido ressaltado o fato de que o componente cultural está intrinsecamente relacionado com a língua. Se a língua há de ser ensinada para a comunicação e interação, esta não poderá ser apresentada estanque, dissociada de sua cultura acompanhante. Cada vez mais teóricos da Linguística Aplicada e de outras áreas correlatas afirmam que é impossível um ensino de línguas adequado, que produza os efeitos almejados, se houver a dissociação desses dois elementos ( $c f$. ALMEIDA FILHO, 2002, p. 210; BROWN, 2007, p. 189). Quando se fala em aquisição de segunda língua, fala-se necessariamente

\footnotetext{
${ }^{1}$ Do original: "Culture is a way of life. It is the context within we exist, think, feel, and relate to others."
} 
em aquisição de segunda cultura (BROWN, op. cit., p. 189, 190). Podemos encontrar nas seguintes palavras de Byram (1997, p. 22) uma confirmação dessa ideia:

Uma vez que a língua é o meio principal de se incorporar a complexidade das práticas e crenças [culturais], por meio de referências e conotações (BYRAM, no prelo) e da inter-relação entre língua e identidade (LE PAGE; TABOURET-KELLER, 1985), a aquisição de uma língua estrangeira é a aquisição das práticas e crenças culturais que ela incorpora para determinados grupos sociais, ainda que o aprendiz também a use de outras formas. ${ }^{2}$

Aprender ou adquirir o que podemos chamar de uma nova ou segunda cultura significa "criar significados compartilhados" entre os representantes das diversas culturas (BROWN, op. cit., p. 194). Ao adquirir e desenvolver capacidade de se comunicar na nova língua, o falante poderá interagir, criando e compartilhando (novos) significados com falantes nativos daquela língua ou com outros falantes que a usam como língua estrangeira.

Tendo em consideração o já mencionado contexto contemporâneo em que se insere o processo de ensino-aprendizagem de línguas, com suas novas demandas e desafios para professor de línguas; a forte relação entre língua e cultura; e a proposta do ensino comunicativo com uma abordagem que visa a desenvolver nos alunos a capacidade de comunicação e interação na língua estudada, passaremos a analisar um conceito que emerge como fundamental neste contexto: a Competência Comunicativa.

\section{Competência comunicativa}

Na história das ciências sociais, e mais recentemente da Linguística Aplicada, diversos teóricos e estudiosos se propuseram a definir a Competência Comunicativa e seus componentes, ou subcompetências (cf. HYMES, 1971; CANALE; SWAIN, 1980; CANALE, 1983; BACHMAN, 1990; CELCE-MURCIA et al., 1995; CANTERO SERENA, 2008). Muitas dessas subcompetências são recorrentes em diversos modelos, que têm como denominador comum a ideia de que a língua está intimamente relacionada ao contexto social e cultural em que se insere. Podemos observar a

\footnotetext{
${ }^{2}$ Do original: "Since language is a prime means of embodying the complexity of those practices and beliefs, through both reference and connotations (Byram, in press a), and the interplay of language and identity (LE PAGE; TABOURET-KELLER, 1985), the acquisition of a foreign language is the acquisition of the cultural practices and beliefs it embodies for particular social groups, even though the learner may put it to other uses to."
} 
recorrência das competências sociocultural/sociolinguística, além da constante referência à capacidade de aplicar os conhecimentos linguísticos à prática da comunicação (Competência Discursiva, em CANALE, 1983; Competência Organizativa, em BACHMAN, 1990; Competência Acional em CELCE-MURCIA et al, 1995; Competência Intercultural, em MENDES, 2004, 2008).

Tais modelos e estudos teóricos indicam que quando um aluno aprende uma nova língua, ele deve tornar-se capaz de ir além do mero domínio de vocabulário e de estruturas e regras de gramática e fonética. A aquisição ou o desenvolvimento da Competência Comunicativa é descrita por alguns teóricos como um dos principais objetivos ou até mesmo o objetivo central do ensino-aprendizagem de línguas (cf. ALMEIDA FILHO, 2007; CANTERO, 2008; CENOZ, 2005; VÉLEZ-RENDÓN, 2002). Por conseguinte, ao acharmos a resposta para a pergunta "o que deve ser ensinado?", ocorre-nos a próxima pergunta: "Qual a melhor forma de ensinar a Competência Comunicativa?" A Abordagem Comunicativa apresenta-se como uma proposta ou tentativa de resposta a essa pergunta.

\section{Abordagem Comunicativa}

A Abordagem Comunicativa surge na década de 70 para oferecer "novas possibilidades de compreensão do processo de aprender/ensinar línguas" (ALMEIDA FILHO, 2007, p. 81). Richards (2002, p. 42) afirma que

o ensino de línguas comunicativo foi uma tentativa de operacionalizar o conceito de Competência Comunicativa e aplicá-lo a todos os diferentes níveis de produção do programa de ensino de língua, desde a teoria até a preparação do plano de curso e técnicas de ensino. ${ }^{3}$

A inovação mais marcante do paradigma comunicativo foi a ênfase no aspecto cultural como intrínseco à língua. Anteriormente, no paradigma estruturalista, língua e cultura apareciam dissociadas, sem qualquer inter-relação. Em contraste, no paradigma comunicativo língua e cultura se unem. Para aprender a comunicar-se na nova língua de forma adequada e efetiva, o falante aprende a usar, além das regras do código, os princípios para aplicar tais regras. Estes princípios são "saberes, crenças e ideias acerca

\footnotetext{
${ }^{3}$ Do original: "Communicative Language Teaching was an attempt to operationalize the concept of communicative competence and to apply it across all levels of language program design, from theory, to syllabus design, to teaching techniques." (RICHARDS, 2002, p. 42)
} 
da realidade e da própria língua que foram interiorizados (...) e que regem o uso efetivo da comunicação" (MIQUEL, 2005, p. 513). O ensino passa a ser centrado no aluno e em proporcionar-lhe oportunidades para ter contato direto com a língua em situações de uso mais próximas do real e daquilo que acontece fora da sala de aula. Tenciona-se também tornar o aluno mais autônomo, capaz de desenvolver sua própria relação com a nova língua e se responsabilizar por aprendê-la, não apenas dentro do ambiente escolar, mas também nas suas extensões (ALMEIDA FILHO, 1993). Em consonância com o incentivo à autonomia do aluno, acontece uma mudança no papel do professor, que deixa de ser o eixo de todo o processo, ou o detentor absoluto do conhecimento ou da "verdade" sobre a nova língua. O professor passa a ser um facilitador, ou orientador. À medida que este professor propõe e estabelece as atividades em sala de aula, passa a aconselhar e monitorar seus alunos, não se mantendo no centro do processo de ensinoaprendizagem (ALMEIDA FILHO, 1997).

Passadas algumas décadas desde que a Abordagem Comunicativa foi sugerida como "promessa de ensino alternativo", Almeida Filho e Barbirato (2000, p. 1) afirmam que "seu potencial ainda está longe de ser esgotado, inquietações ainda restam e mais estudos são necessários”. Concordamos que a Abordagem Comunicativa não almeja ser, nem deveria ser aclamada como a solução definitiva ou o caminho perfeito para o ensino de línguas. Antes, é razoável encará-la como uma sugestão de abordagem que busca atender às demandas de um ensino de línguas para a comunicação apresentadas pelo contexto contemporâneo. Assim sendo, a pergunta de pesquisa que abordaremos neste artigo é a seguinte: Como os preceitos fundamentais para a Abordagem Comunicativa e para o ensino da Competência Comunicativa são abordados durante o curso de Licenciatura?

\section{Metodologia da pesquisa}

A pesquisa descrita neste artigo foi um estudo de caso qualitativo, visto que buscamos investigar fenômenos específicos acerca dos cursos de formação de professores (FALTIS, 1997, p. 145; GIL, 2008, p. 27; NUNAN, 1997, pp. 77, 78). Buscamos observar os princípios éticos, tratando as participantes por codinomes, visando garantir-lhes completa privacidade. Ademais, todas as participantes assinaram um Termo de Consentimento Livre e Esclarecido, indicando que partilham dos 
interesses do pesquisador e concordam em participar fornecendo as informações necessárias para a realização da investigação.

\section{Contexto da pesquisa, participantes e instrumentos e coleta de dados}

Este estudo foi realizado no segundo semestre de 2009 e no primeiro semestre de 2010 em uma universidade pública brasileira. O Instituto de Letras daquela universidade oferece cinco cursos de licenciatura plena para formar professores de línguas. Desses cursos, foram escolhidos três que consideramos ter maior expressividade em número de professores formados e atuantes como tal, a saber, os cursos de Letras Licenciatura em Línguas Espanhola, Francesa e Inglesa. Para cada curso foram selecionadas três professoras em formação que estavam cursando as disciplinas de estágio e uma professora formadora. Desta forma, para cada curso de Licenciatura temos quatro participantes, perfazendo um total de 12 pessoas.

Utilizamos questionários abertos com cerca de 27 perguntas, tendo por objetivo verificar pontos específicos e obter uma visão geral das informações e pontos de vista das participantes. As questões foram abertas, porque dão ao participante certa medida de liberdade ao se expressar (NUNAN 1997, p.143).

A seguir apresentamos os resultados da análise de dados.

\section{Apresentação e discussão dos dados}

A princípio está registrada a análise dos dados obtidos através dos questionários aplicados às professoras em formação. Em seguida, será apresentada a análise dos dados obtidos dos questionários respondidos pelas professoras formadoras.

As categorias de análise encontram-se no quadro a seguir.

Quadro 1: Categorias de análise

\begin{tabular}{|l|l|}
\hline Professoras em formação & Professoras formadoras \\
\hline Papel do professor & Abordagem Comunicativa \\
\hline Abordagem Comunicativa & Competência Comunicativa e seu ensino \\
\hline Competência Comunicativa e seu ensino & Observação de Estágio \\
\hline Observações de Estágio & \\
\hline Língua, cultura e elementos socioculturais & \\
\hline
\end{tabular}




\section{Professoras em Formação}

\section{Papel do Professor}

A pergunta para este tópico foi: "Na sua opinião, qual é o papel do professor de línguas na contemporaneidade?”. De forma geral, as participantes demonstraram ter uma clara noção do papel do professor de línguas como mediador e facilitador no processo de ensino-aprendizagem, não como detentor do conhecimento. O professor é descrito como monitorando o aluno e atuando como facilitador do processo de aprendizagem. Percebe-se também a compreensão de que o objetivo final do processo de ensino-aprendizagem de línguas é a comunicação, e que elementos culturais estão ligados à língua.

\section{[Excerto 1 PEF]}

Bianca, inglês: "Mediar o aprendizado de uma nova língua/cultura de forma que o próprio aluno possa não somente adquirir conhecimento, mas formar opinião crítica quanto ao aprendizado."

Kate, inglês: “(...) Não basta ensinar somente a língua, mas é necessário também contextualizá-la."

Edite, francês: “(...) formar pessoas capazes de se comunicarem e se adaptarem as diversas situações de comunicação."

Elise, francês: "É contribuir na sensibilização do aluno no aprendizado do língua e da cultura de determinada língua."

Ana, espanhol: "Orientar o aprendizado do aluno, fazendo a relação entre o estudo e o uso no dia-a-dia."

\section{Abordagem Comunicativa}

As perguntas apresentadas sob este tópico tinham como objetivo verificar se as participantes tinham ou não conhecimento sobre a Abordagem Comunicativa e se consideravam que tal abordagem era apresentada de maneira satisfatória durante o curso. Com base nas respostas, podemos concluir que as participantes demonstram desconhecimento ou falta de clareza na compreensão de o que o conceito da Abordagem Comunicativa abarca. Isso pode ser ilustrado com a expressão de Elise, da Licenciatura em Língua Francesa, que afirmou que considera que a Abordagem Comunicativa seja tratada de maneira satisfatória no seu curso "pois são trabalhados de maneira satisfatória a gramática, a fonética e a pronúncia”. 
Mesmo sem demonstrar conhecimento profundo dos conceitos fundamentais da Abordagem Comunicativa, as demais participantes são capazes de caracterizar o curso como estruturalista e não comunicativo. Vejamos algumas dessas expressões:

\section{[Excerto 2 PEF]}

Nicole, inglês: "O curso está mais focado em matérias que garantem ao futuro professor conhecimentos de gramática, vocabulário, literatura... Não há matérias que efetivamente auxiliem no desenvolvimento das competências." Edite, francês: "Algumas competências, como a gramatical, são até bem trabalhadas. Entretanto, não existem oportunidades para trabalhar a parte da comunicação."

Lurdes, espanhol: "[O curso] ainda está muito preso a estrutura e gramática."

Ana, espanhol: "(...) As disciplinas de literatura e o conhecimento cultural são poucas para tratar de tantos assuntos."

As participantes manifestaram ainda sua insatisfação quanto ao espaço dado à Abordagem Comunicativa durante o curso. Em uma questão fechada, pedimos que elas avaliassem o currículo do curso quanto a formar professores para atuar dentro dos preceitos da Abordagem Comunicativa. ${ }^{4}$ A maioria das participantes escolheu a alternativa que afirma que a Abordagem Comunicativa é tratada em algumas disciplinas, mas não de forma suficientemente abrangente. Uma das participantes escolheu a alternativa de que a Abordagem Comunicativa é apresentada por diferentes professores, em diferentes ocasiões, mas não como parte específica de uma disciplina.

Seguem algumas respostas:

\section{[Excerto 3 PEF]}

Lurdes, espanhol: "Um aprofundamento do conteúdo seria importante e daria mais desenvoltura."

Ana, espanhol: "Os requisitos e as necessidades da Abordagem Comunicativa não são explicados."

Nicole, inglês: "A maioria dos conteúdos é abordada de forma superficial."

Kate, inglês: "O aluno acaba não tendo muito contato com essas modalidades de ensino" e "os alunos deveriam estar mais expostos a essas abordagens desde o início do curso, para que no fim eles a dominem de forma mais satisfatória."

Bianca, inglês: "Faltam matérias que levem em consideração que o curso de Letras forma, em sua maior parte, professores, e estes devem estar cientes da

4. A pergunta e as alternativas foram: Como você avalia o atual currículo do curso de Licenciatura em Língua Inglesa e Respectiva Literatura quanto a formar professores para atuar dentro dos preceitos da Abordagem Comunicativa? (a) Existem suficientes disciplinas que tratam da fundamentação teórica da Abordagem Comunicativa; (b) Algumas disciplinas tratam da fundamentação teórica da Abordagem Comunicativa, mas não de forma suficientemente abrangente; (c) A Abordagem Comunicativa é apresentada por diferentes professores em diferentes ocasiões do curso, mas não necessariamente como parte de uma disciplina específica; (d) Tenho outra opinião. Explique. 
Abordagem Comunicativa" e "o curso ensina a abordagem apenas na matéria de Metodologia, quando deveria ser tratada desde o início."

Competência comunicativa e seu ensino

De forma geral, as participantes consideram que as subcompetências da Competência Comunicativa são abordadas superficialmente ou de forma fragmentada e esparsa, sem o aprofundamento necessário. A maioria das participantes tem algum entendimento dos diversos conceitos e de como ou em que disciplinas essas subcompetências poderiam ser compreendidas e adquiridas por elas como professoras, para então poderem auxiliar seus alunos. No entanto, este entendimento não está sistematizado e não advém de uma abordagem satisfatória de tais conceitos oferecida pelo curso de Licenciatura. Não percebemos, em nenhum momento, uma completa satisfação em relação à forma como essas subcompetências são abordadas pelo curso.

A respeito do ensino da Competência Comunicativa, procuramos saber se as participantes consideram que durante o curso puderam construir uma base de conhecimento dos preceitos fundamentais da Abordagem Comunicativa suficiente para ter bom desempenho no ensino da Competência Comunicativa e suas subcompetências.

Conforme suas respostas, dividimos as participantes em dois grupos principais. O primeiro grupo, representado por sete participantes, expressou que sente que o aprendizado que tiveram da Competência Comunicativa e de suas subcompetências foi pouco, insuficiente para torná-las seguras para a prática. Em alguns casos, as participantes afirmam que esse conhecimento foi complementado por disciplinas optativas ou por experiências e estudos realizados fora da universidade. As mesmas salientam sua percepção de que o curso não é "exigente" em relação ao ensino da Competência Comunicativa.

O segundo grupo, representado por duas participantes, afirma que durante o curso de Licenciatura aprenderam "um pouco" do que gostariam, mas que esperam continuar a aprender também à medida que ensinam, na prática docente. Separamos essas expressões em um segundo grupo porque, apesar de também declararem que aprenderam pouco, não percebemos que as participantes atribuem esse pouco aprendizado à estrutura do curso, mas parecem encará-lo como natural, uma vez que esse conhecimento deverá ser complementado pela prática. 
A seguir, estão relacionadas as respostas que apóiam os entendimentos descritos anteriormente:

\section{[Excerto 7 PEF] \\ Primeiro grupo}

Kate, inglês: "Parcialmente, pois poderia haver mais disciplinas com esse enfoque acerca da Competência Comunicativa e suas subcompetências."

Nicole, inglês: "O pouco que aprendi sobre essa competência foi adquirido, em sua grande maioria, em matérias fora da grade curricular obrigatória do curso."

Amelie, francês: "Parcialmente pela universidade em que estudo e um centro de línguas. Na universidade em que estudo não temos uma política de falar somente em francês tanto nas aulas como nos corredores, o curso não é muito "exigente" no sentido de que não há uma grande cobranças dos professores, aliás, várias matérias nem professor tem."

Edite, francês: "Acredito que alguns aspectos foram bem trabalhados. Entretanto, não me sinto completamente segura para trabalhar todas as competências dentro de sala de aula."

Maria, espanhol: "Sinto que faltou um nível de exigência maior, algo que acrescentasse. Tirando a literatura, nas outras matérias me senti estagnada."

Lurdes, espanhol: "Não consegui uma fluência satisfatória."

Ana, espanhol: "Ainda faltam alguns conhecimentos a serem aprofundados. Ademais, muitas vezes estudamos alguns conteúdos sem saber depois como aplicá-los".

\section{Segundo grupo}

Bianca, inglês: "O curso me ensinou um pouco do que eu gostaria de aprender e espero alcançar o restante com a experiência profissional."

Elise, francês: "Na verdade não sabemos tudo e aprendemos, também, quando ensinamos."

\section{Observações de estágio}

Neste tópico, investigamos se as participantes consideram que em suas avaliações de estágioos professores levam em conta o domínio do ensino da Competência Comunicativa. Em resposta, oito participantes afirmaram que sim, apenas uma escolheu "não" como resposta e justificou como se segue: "De forma alguma. Pelos critérios de avaliação apresentados pelo orientador de estágio não há qualquer consideração ao domínio do ensino da Competência Comunicativa e suas subcompetências." Duas participantes que escolheram 'sim' justificaram apenas com características subjetivas das professoras, como "Pelo menos se esforça muito" e "As professoras e coordenadoras são super competentes para isso". Uma participante afirmou que sim em virtude de o local onde o estágio foi realizado adotar a Abordagem Comunicativa como metodologia de ensino. Percebemos que esses três comentários não 
revelam diretamente algo sobre a avaliação que a professora deve fazer da prática de estágio.

Outras duas participantes justificaram a escolha do 'sim' com expressões genéricas, ou termos vagos, que não fornecem resposta específica. Conforme entendemos, essas respostas também não apontam para uma conduta ou prática específica da professora que as avaliou. Seguem-se as expressões:

\section{[Excerto 8 PEF]}

Elise, francês: "Toda avaliação deve $\operatorname{ser}^{5}$ completa, tanto de domínio da turma como de conteúdo."

Edite, francês: "Acredito que durante a avaliação o professor busque avaliar todas as subcompetências do estagiário."

Por fim, avaliamos que a resposta de uma participante aproximou-se mais de uma avaliação objetiva. Ela respondeu que "as professoras buscam ver [nelas] uma visão menos tradicional e mais comunicativa". Não explicou, porém, o que significa essa "visão comunicativa" ou como as professoras fazem essa avaliação.

A seguir, perguntamos se as participantes consideravam que o domínio do ensino da Competência Comunicativa era devidamente avaliado ou se deveria ser mais enfatizado. A resposta de duas das participantes da Licenciatura em Língua Inglesa indica que a avaliação feita pelo professor é correspondente, ou equivalente, ao que é apresentado sobre a Abordagem Comunicativa durante o curso. Observamos tais respostas a seguir:

\section{[Excerto 9 PEF]}

Kate, inglês: "É devidamente avaliado pelo professor, pois como o curso não nos fornece uma base tão enfática a respeito dessas abordagens, o professor deve avaliar proporcionalmente ao que foi ministrado e ofertado durante o curso."

Nicole, inglês: "Eu acho que o domínio do ensino da Competência Comunicativa e suas subcompetências é pouco enfatizado, mas isso é coerente com o tanto que se fala dessa competência durante os três anos e meio de graduação. Não se faz qualquer menção direta a ela, então, não se exige muito."

As demais participantes afirmam que sim, o domínio do ensino da Competência Comunicativa é devidamente avaliado pelas professoras. Entretanto, não conseguimos agrupar essas quatro respostas para uma conclusão específica visto que são bem diferentes umas das outras. Uma participante respondeu apenas "sim", mas não

\footnotetext{
${ }^{5}$ Grifos dos autores.
} 
justificou. Outra afirmação foi, novamente, que "as professoras e coordenadoras são super competentes para isso", a qual, conforme citado, não nos fornece dados específicos para uma avaliação do ponto em questão. Seguem-se outras duas respostas que nos fornecem algumas informações:

\section{[Excerto $10 \mathrm{PEF}$ ]}

Maria, espanhol: "É bem avaliado. Eles são pontuais em relação à nossa prática em sala, aquilo que se desvia do objetivo comunicativo é analisado e orientado a mudar."

Elise, francês: "O professor de estágio possui ferramentas suficientes para avaliar o futuro professor por meio dos planos de aulas, das provas elaboradas, das observações em sala de aula."

Com essas duas respostas percebemos nas professoras em formação a noção de que durante o estágio sua prática é avaliada segundo critérios provavelmente claros que lhes são dados a conhecer. Podemos concluir também que, aparentemente, acontece a posterior discussão da avaliação do estágio e uma correspondente orientação acerca de como ajustar a prática. Assim sendo, percebemos que as participantes demonstram ter diferentes impressões e opiniões acerca da avaliação de estágio.

\section{Língua, cultura e elementos socioculturais}

Pedimos às participantes que definissem língua, em seguida cultura e, por fim, a relação entre as duas. Das nove participantes, cinco definiram língua como um sistema, de signos, de comunicação ou gramatical. Com exceção de duas participantes, todas mencionaram comunicação e expressão como funções do uso da língua. Seis participantes mencionaram o caráter coletivo e de interação do uso da língua, com expressões como "comunidade de indivíduos", "interação entre os sujeitos", "grupo de indivíduos", “coletividade”, “entre seres-humanos”, “do país”, “entre um povo”. Foram citados ainda os aspectos culturais e históricos.

As expressões acima demonstram uma compreensão de língua ainda um pouco vinculada aos moldes estruturalistas, mas já caminhando em direção a uma compreensão mais contemporânea em conformidade com o entendimento apoiado por estudos e pesquisas da Linguística Aplicada e de áreas afins. Uma possível tentativa de unificar as ideias apresentadas pelas participantes em uma única definição seria: Língua 
é um sistema de signos utilizado para expressão e comunicação que identifica um determinado grupo de pessoas e abrange aspectos culturais e históricos deste povo.

Para a definição de cultura, as participantes incluíram elementos da produção cultural, como manifestações artísticas e intelectuais, música e dança. Curiosamente, não houve qualquer menção à literatura. Entre as respostas figuram ainda elementos referentes à atuação das pessoas dentro da sociedade, como tradições, costumes, manifestações religiosas, comportamentos, posturas, falas, expressões, ditos, provérbios, crenças, valores, identidade, visão de mundo, história, fenômenos sociais, jeito de se comportar, viver e ser, hábitos e costumes. Das nove participantes, oito citaram o caráter coletivo da cultura, o que pode ser percebido pelas seguintes expressões: "[aspectos que] caracterizam/definem um povo", "aspectos de uma sociedade", "elementos sociais comuns a um dado grupo de pessoas", "tudo aquilo que é produzido pelo meio de uma coletividade de pessoas, grupo, raça”, "características comuns a um determinado grupo/povo", "expressão da visão, da história (...) que um povo vive e registra". As expressões acima descritas parecem abranger os aspectos básicos presentes nas definições de cultura mencionadas na fundamentação teórica, de forma que nos levam a concluir que as participantes demonstram um entendimento razoável de o que é cultura.

Por fim, quanto à relação entre língua e cultura, as participantes mencionaram uma influência direta e recíproca. Entendemos ainda que o uso de algumas expressões parece buscar ressaltar o grau de ligação entre língua e cultura, como, por exemplo, em: "inseparáveis", "intimamente relacionadas" e "interligadas". Seguem alguns dos comentários mais representativos:

\section{[Excerto $11 \mathrm{PEF}$ ]}

Kate, inglês: "Língua e cultura são instrumentos inseparáveis, a língua é uma expressão da cultura, ambas possuem influência uma sobre a outra."

Bianca, inglês: "O uso da língua tem conseqüências na cultura, assim como a cultura também tem o poder de modificar a língua."

Nicole, inglês: "Uma língua e sua cultura estão relacionadas de forma direta e uma influencia a outra de forma constante e simultânea."

Amelie, francês: "A língua está inserida na cultura e a cultura na língua."

Edite, francês: "A língua e a cultura estão intimamente relacionadas. Afinal, a língua carrega consigo toda a cultura de uma sociedade."

Ana, espanhol: "A língua de um povo sofre influencia direta de sua cultura, que modifica e adapta à sua realidade." 
Com as duas últimas perguntas procuramos saber das participantes como elas compreendem o conceito de "elementos socioculturais" e pedimos também que fornecessem exemplos de como alguma disciplina tratou aspectos ou fenômenos socioculturais. Quatro participantes citaram como elementos socioculturais aspectos como literatura, arte, dança, música, filmes; outras citaram culinária, festas e tradições e ainda estratificação social e o caráter histórico/evolutivo dos elementos socioculturais. As disciplinas de Civilização e de Cultura e Instituições foram citadas pelas participantes como tratando de aspectos socioculturais. Uma única participante incluiu na respostas um exemplo de como o professor aborda tais elementos. Edite, da Licenciatura em Língua Francesa, comentou o seguinte acerca das aulas de Civilização Francesa: "O professor tentou ao máximo nos inserir dentro da realidade daquele país. Dentro de sala de aula ele trabalhava com materiais como jornais semanais franceses. A análise desses jornais semanalmente nos permitia ver o que estava acontecendo na sociedade francesa, além de termos a oportunidade de ver as diferentes formas de como a língua pode ser empregada." Outras duas participantes acrescentaram alguns detalhes depois de citar as disciplinas, como vemos a seguir:

\section{[Excerto $12 \mathrm{PEF}$ ]}

Elise, francês: "Civilização Francesa e Civilizações de Expressão Francesa trataram das diferenças dos falantes da mesma língua, de seus costumes e cultura."

Ana, espanhol: "As disciplinas de Metodologia de Análise de Textos e Usos Especializados tratam desses aspectos socioculturais (...) nos dá noção de que o uso da língua muitas vezes está relacionado a outros sentidos além do literal.”

Em contraste com os comentários citados acima, identificamos duas participantes com informações diferentes, que não puderam agrupadas com as anteriores. Uma delas afirmou que não se recorda de nenhuma matéria, como segue:

\section{[Excerto $13 \mathrm{PEF}$ ]}

Nicole, inglês: "Durante o processo de graduação não me recordo de ter cursado alguma matéria que tenha contribuído para que eu ficasse ciente dessa diferença. Consigo perceber essa ciência como algo anterior ao ingresso na universidade onde estudo, durante meu curso de inglês em instituição particular e pelas experiências adquiridas em viagens e em filmes, seriados, músicas, etc. da língua inglesa."

Outra participante relaciona o conhecimento de fenômenos socioculturais a outros fatores, que não às aulas. Segue o comentário: 
[Excerto $14 \mathrm{PEF}$ ]

Bianca, inglês: "A observação de aulas em instituições públicas e privadas me fez analisar alguns aspectos, práticas e condutas de cada universo, proporcionando um conhecimento maior sobre esses fenômenos socioculturais e as habilidades que demandam de um professor, para que o mesmo lide corretamente com as diferenças em sala de aula."

Essa resposta parece indicar que a participante relaciona os aspectos e fenômenos socioculturais à prática docente em sala de aula e, possivelmente, aos desafios com os quais o professor se depara. A resposta não aponta para uma compreensão de que os elementos culturais são constituintes de uma língua e sua cultura. Essa última resposta guarda relação com a anterior, de Nicole, no sentido de que não identifica no curso, ou em disciplinas específicas, o entendimento e o contato com o conceito de elementos culturais.

A seguir, apresentamos a análise de dados dos questionários respondidos pelas professoras formadoras.

\section{Professores formadores}

\section{Abordagem comunicativa}

As três professoras formadoras concordam unanimemente que o ensino de línguas deve acontecer tendo a comunicação como objetivo principal. Apenas uma das professoras discorda de que a Abordagem Comunicativa dever ser o modelo ou paradigma adotado para o ensino de línguas na contemporaneidade. Segue sua justificativa:

\footnotetext{
[Excerto $15 \mathrm{PF}$ ]

Isabel: “A língua deve ser ensinada para a comunicação e, quanto a isso, não há dúvidas. No entanto, na escolha da abordagem ou metodologia a ser utilizada, vários fatores precisam ser considerados, entre estes, os objetivos do curso em questão. Além disso, como destaca Prahbu (1992), o professor deve ter um senso de plausibilidade em suas tomadas de decisões em sala de aula. (...) Além disso, vários fatores influenciam a abordagem de ensinar do professor, como suas experiências de aprendizagem anteriores e suas crenças."
}

As outras duas professoras concordam que a Abordagem Comunicativa deve ser o paradigma adotado para o ensino de línguas na contemporaneidade. Uma delas 
justificou que "no mundo globalizado em que vivemos, mostra-se necessário um ensino que vise à comunicação levando em conta o desenvolvimento de competências, orais e escritas". A terceira professora afirma que "a língua se aprende para a comunicação" e que, nesse contexto, a gramática deve ser aprendida de forma funcional.

Quanto às avaliações relativas como curso apresenta a Abordagem Comunicativa, as duas professoras concordaram que esta abordagem não é apresentada de forma satisfatória pelo curso. Uma delas acrescentou que "ainda há muito caminho por andar", e a outra professora afirmou que "ainda nos dias de hoje, muitos professores não compreendem bem o que significa ser comunicativo e muitos ainda se intitulam comunicativos, quando, na verdade, ensinam de forma tradicional". Sobre o currículo do curso e o oferecimento de disciplinas que tratem da Abordagem Comunicativa, as duas professoras afirmaram que as disciplinas existentes não contemplam de maneira satisfatória a fundamentação da Abordagem Comunicativa e não auxiliam de forma suficiente no desenvolvimento da habilidade de escrita. Uma das professoras citou "as novas disciplinas optativas de Linguística Aplicada" como exceção do que foi dito anteriormente. Seguem algumas partes dos comentários feitos pelas professoras contendo mais considerações acerca das disciplinas:

\section{[Excerto $16 \mathrm{PF}$ ]}

Isabel: "O currículo é antigo e bastante estruturalista, o que se pode observar até mesmo no modelo que separa as habilidades a serem ensinadas em diferentes semestres ao longo do curso. As disciplinas que tratariam do desenvolvimento de algumas competências importantes para a atuação do professor em uma abordagem mais comunicativa estão concentradas nos últimos semestres e limitadas a uma carga-horária bastante reduzida.

Lídia: Na disciplina que poderia ser incluído esse aspecto seria na de Metodologia. Mas acredito que deveria se pensar em uma disciplina específica para tratar sobre os estilos e estratégias de aprendizagem, assim como as habilidades e competências."

Percebemos nessa breve avaliação sobre a Abordagem Comunicativa e o currículo dos cursos de Licenciatura que as professoras têm opiniões congruentes, crêem que as disciplinas presentes no currículo tratam dos preceitos da Abordagem Comunicativa tardiamente e de forma insuficiente. 
Para que o ensino da Competência Comunicativa passe a ser satisfatório e eficiente, as professoras formadoras opinam que devem ser adotadas disciplinas com as seguintes características:

- Disciplinas sobre as competências e habilidades necessárias ao professor;

- Disciplinas sobre estilos e estratégias de aprendizagem;

- Disciplinas que propiciem ao aluno o desenvolvimento de uma consciência intercultural;

- Disciplinas da Linguística Aplicada (incluindo disciplinas de Avaliação e Elaboração de Material Didático para o ensino comunicativo, assim como Avaliação da Aprendizagem) que poderiam ser ofertadas, em caráter mais específico, em substituição aos conjuntos de disciplinas ofertadas pela área de Educação;

- Disciplinas de gramática, hoje apresentadas de forma isolada, que passassem a privilegiar o contexto e o ensino da cultura;

Observamos nas respostas das professoras a necessidade de que os currículos dos cursos deem maior ênfase ao embasamento teórico para o ensino de línguas comunicativo, bem como para o ensino de cultura. Ressaltam ainda que deve haver a contextualização do ensino de línguas, para incentivar a prática dos professores em formação, de modo que estes consigam auxiliar seus alunos no desenvolvimento pleno da Competência Comunicativa.

\section{Observação de estágio 6}

A professora formadora afirma que são constatados "muitos" déficits no domínio do ensino de uma ou mais das subcompetências que compõem a Competência Comunicativa. Ela afirma: "Os estagiários acreditam que saber ensinar a LE se reduz ao ensino da gramática, por essa razão concentram sua atenção nesse aspecto. As demais competências e subcompetências não são observadas. Na verdade, como não foram desenvolvidas durante o curso, não há como detectá-las." Vemos, com isso, que é

\footnotetext{
${ }^{6}$ Durante o período da realização da pesquisa conseguimos ter acesso a apenas uma professora formadora que estava lecionando a disciplina de Estágio Supervisionado. Portanto, constaram aqui apenas as respostas desta professora.
} 
provável que ao fim do curso de Licenciatura a maioria dos professores recém-formados estejam espelhando o que lhes foi ensinado ao longo do curso e, assim, apresentam uma forma de ensinar estruturalista, fortemente voltada para o ensino de gramática.

Quanto à sua própria avaliação nas disciplinas de Estágio Supervisionado, a professora afirma que, no seu caso, busca fazê-la "de forma muito flexível, pois não podemos cobrar aquilo que não foi dado". Mais uma vez percebemos no depoimento da professora a lacuna deixada pela estrutura do curso, que fica mais claramente observável nos estágios finais onde ocorre a prática. Esse quadro impossibilita à professora da disciplina de Estágio Supervisionado exigir dos professores em formação um ensino comunicativo, visto que este não esteve presente em sua formação.

\section{Considerações finais}

Neste estudo, buscamos investigar a formação oferecida por três cursos de Licenciatura do Instituto de Letras de uma universidade pública, quanto a se esta corresponde ao que postula e exige o paradigma comunicativo contemporâneo. Em outras palavras, procuramos saber se estão presentes nos cursos de formação elementos suficientes que garantam ao professor recém-formado uma base de conhecimento teórico e oportunidades de prática satisfatórias que lhe permitam atuar com segurança para um ensino de línguas comunicativo.

Como conclusão acerca das participações das professoras em formação, podemos observar que elas demonstraram um bom entendimento do papel do professor como facilitador no processo de ensino-aprendizagem de línguas. Com relação ao entendimento dos fundamentos do ensino comunicativo e das características da Competência Comunicativa, as respostas indicam que, de forma geral, as professoras em formação não demonstram ter um entendimento claro e pontual dos elementos teóricos centrais e da natureza complexa da Competência Comunicativa.

A respeito dos elementos socioculturais, as participantes, de modo geral, demonstraram ter um conhecimento e entendimento razoável, que poderia facilmente evoluir para a compreensão desejada em consonância com os estudos teóricos mais recentes. Ainda em relação à prática do ensino comunicativo, as participantes, em sua maioria, declararam não se sentirem completamente seguras, tanto em virtude das 
lacunas presentes na base de sua formação como de falhas por elas detectadas nas observações de estágio.

Observamos por parte das professoras formadoras uma clara percepção de que o currículo e a estrutura dos cursos de Licenciatura não podem ser descritos como comunicativos ou como estando em consonância com a produção da teoria contemporânea para o ensino de línguas. Como professoras formadoras demonstram ter clareza na compreensão de quais são as lacunas apresentadas pela estrutura do curso, entendem que estas devem ser sanadas com brevidade, e se mostram ainda plenamente capazes de indicar como essas deficiências podem ser corrigidas. Demonstram também que buscam, em sua prática docente individual, esforçar-se para compensar, da forma como podem, essas falhas e buscam orientar seus alunos em direção ao desenvolvimento da Competência Comunicativa e da compreensão geral de o que o ensino comunicativo abrange. Podemos afirmar ainda que, ao contemplarmos as expressões das professoras que colaboraram como esta pesquisa, torna-se nítida a necessidade de uma reforma curricular que possa vir ao encontro das necessidades contemporâneas apresentadas aos professores de línguas, a saber, que os referidos cursos formem professores capazes de praticar o ensino comunicativo e de auxiliar seus alunos a desenvolver a comunicação e interação como uma forma de encontro entre diferentes "sujeitos-mundos culturais diversificados" (MENDES, 2008, p. 58).

Acreditamos que esta pesquisa poderá contribuir com dados específicos, científicos e sistematizados que indicam a necessidade urgente de uma reforma curricular para se alcançar a adequação dos de Licenciatura aos grandes estudos e entendimentos teóricos já disponíveis no meio acadêmico-científico. Destacamos estudos e pesquisas científicos desenvolvidos por estudiosos da Linguística Aplicada, que provaram-se capazes de fornecer excelente base teórica para a formação de professores de línguas aptos a desempenhar bem seu papel na contemporaneidade.

\section{Referências}

ALMEIDA FILHO, José Carlos P. Linguística aplicada, ensino de línguas $e$ comunicação. 2 ed. Campinas: Pontes; ArteLíngua, 2007. 
Língua além de cultura ou além de cultura, língua? Aspectos do ensino da interculturalidade. In: CUNHA, Maria J. C.; SANTOS, Percília (Orgs). Tópicos em português língua estrangeira. Brasília: Ed. da Universidade de Brasília, 2002.

Crise, transições e mudança no currículo de formação de professores de línguas. In: FORTKAMP, Mailce.; TOMITCH, Leda. Aspectos da linguística aplicada. Florianópolis: Insular, 2000. p. 33-47.

1999.

(Org.). O professor de língua estrangeira em formação. Campinas: Pontes,

Parâmetros atuais para o ensino de português língua estrangeira. Campinas: Pontes, 1997.

Dimensões comunicativas no ensino de línguas. Campinas: Pontes, 1993.

ALMEIDA FILHO, José Carlos P.; BARIBIRATO, Rita C. Ambientes comunicativos para aprender língua estrangeira. Trabalhos em Linguística Aplicada. v. 36, p. 23-42, jul/dez 2000. Disponível em: <http://www.let.unb.br/jcpaes/artigos_publicados.html>. Acesso em: 21 jun. 2010.

BACHMAN, Lyle. F. Fundamental considerations in language testing. Oxford: Oxford University Press, 1990.

BROWN, H. Douglas. Principles of language learning and teaching. 5th ed. Englewood Cliffs/New Jersey: Prentice-Hall Regents, 2007.

BYRAM, Michael. Teaching and assessing intercultural communicative competence. Clevedon: Multilingual Matters, 1997.

CANALE, Michael. From communicative competence to communicative language pedagogy. IN: RICHARDS, Jack. C.; SCHMIDT, Richard W. (Eds.). Language and communication. London; New York: Longman, 1983.

CANALE, Michael.; SWAIN, Merrill. Theoretical bases of communicative approaches to second language teaching and testing. Applied Linguistics. v. 1, p. 1-47, 1980.

CANTERO, Francisco J. Complejidad y competencia comunicativa. Horizontes de Lingüística Aplicada, v. 7, n. 1, p. 71-87, 2008. Disponível em: <http://www.revistahorizontes.unb.br/images/horizontes/07_01_2008/horizontes_01_07 _01_2008_CANTERO.pdf>. Acesso em: 20 jun. 2010.

CELCE-MURCIA, Marianne; DÖRNYEI, Zoltán; TURRELL, Sarah. A pedagogically motivated model with content specifications. Issues in Applies Linguistics, v. 6, p. 5-35, 1995.

CENOZ, Jasone I. El concepto de competência comunicativa. In: GARGALLO, Isabel S.; LOBATO, Jesus S. (Dir.). Vademecum para la formación de profesores: enseñar español como segunda lengua (L2) / lengua extranjera (LE). Madrid: SGEL, 2005. 
DURHAM, Eunice. Entrevista à Revista Veja, edição 2088, de 26 de novembro de 2008. Disponível em: <http://veja.abril.com.br/261108/entrevista.shtml>. Acesso em: 18 mar. 2010.

FALTIS, Christian. Case study methods in researching language and education. In: Hornberger, Nancy; Corson, David. (Eds.). Research methods in language and education. Encyclopedia of Language and Education, v. 8. Dordrecht: Kluwer Academic Publishers, 1997.

GIL, Antônio Carlos Métodos e técnicas em pesquisa social. São Paulo: Atlas, 2008.

HYMES, Dell H. Competence and performance in linguistic theory. IN: HUXLEY, Renira; INGRAM, Elisabeth. (Eds.). Acquisition of languages: models and methods. Nova Iorque: Academic Press, 1971.

KRAMSCH, Claire. Language and culture. New York: Oxford University Press, 1988.

MENDES, Edleise. Abordagem comunicativa intercultural (ACIN): uma proposta para ensinar e aprender língua no diálogo de culturas. Tese (Doutorado em Linguística Aplicada) - Instituto de Estudos da Linguagem, UNICAMP, Campinas, 2004.

Língua, cultura e formação de professores: por uma abordagem de ensino intercultural. In: MENDES, E.; CASTRO, M. L. S. (Orgs.). Saberes em português: ensino e formação docente. Campinas, SP: Pontes, 2008.

MIQUEL, L. L. La subcompetência sociocultural. In: GARGALLO, I. S.; LOBATO, J. S. (Dir). Vademecum para la formación de profesores - enseñar español como segunda lengua (L2) / lengua extranjera (LE). Madrid: SGEL, 2005.

NÓVOA, A. O professor se forma na escola. Nova Escola, seção Fala Mestre, ano XVI, n. 142 , p. 13-15.

NUNAN, David. Research method in language learning. Cambridge: Cambridge University Press, 1997.

RAJAGOPALAN, Kanavillil. Por uma lingüística crítica: linguagem,identidade e questão ética. São Paulo: Parábola, 2003.

RICHARDS, J. C. Theories of teaching in language teaching. In: RICHARDS, J. .C ; RENANDYA, W. (Eds.). Methodology in language teaching: an anthology of current practice. Cambridge: Cambridge University Press, 2002. p. 39-45.

VÉLEZ-RENDON, G. Second language teacher education: a review of the literature. Foreign Language Annals, vol. 35, n. 4, p. 457-467, 2002. 